Check for updates

Nuffield Trust, London, UK

Twitter @markgdayan Cite this as: $B M / 2021 ; 375: n 3119$ http://dx.doi.org/10.1136/bmj.n3119 Published: 20 December 2021

\title{
The impact of Brexit on health is only just beginning
}

\section{Brexit uncertainty adds another dimension of disruption to a health service already struggling with the unknown legacy of a global pandemic}

\author{
Mark Dayan policy analyst and head of public affairsBrexit programme lead
}

Two years ago, Boris Johnson won the keys to 10 Downing Street on a promise to "get Brexit done," bringing stability and certainty. But a year after the second of two bitterly fought treaties negotiated with the EU entered into force, Brexit remains a source of uncertainty, doubt, and dizzying changes in direction.

The Nuffield Trust's new report today, funded by the Health Foundation, looks back on the health implications of the first few months of disconnection from European markets and institutions. ${ }^{1}$ In almost every area we find that the effects are only just beginning to unfold, with stability often slowed by a lack of clear decisions.

The most obvious case is in Northern Ireland. Both the UK government and the European Commission agree that the country effectively remaining within the EU single market, as agreed by Johnson's government in 2019, poses problems for medicines supply-possibly threatening almost a thousand product lines. ${ }^{2}$ Northern Ireland is traditionally supplied through Great Britain, but the regulatory divide will make this costly and difficult when full controls enter into force-in just two weeks' time.

Each side has tendered its own proposals. The UK has requested that Northern Ireland's alignment with the EU in medicines should cease to exist altogether. ${ }^{3}$ The EU published draft legislation last Friday for a wide range of special provisions, allowing quality control and approvals in the UK to work for Northern Ireland as long as they follow EU law. ${ }^{4}$ Both proposals have weaknesses. The UK's suggestion creates a divide at the border with the Republic of Ireland and is difficult to reconcile with the basic aims of the Protocol. While the EU provisions solve many specific problems, they would not restore free movement, and manufacturers have told us that the divide in regulatory systems between Northern Ireland and the rest of the UK is a problem for supply in itself.

Endless brinksmanship, including repeated threats by the UK to suspend the treaty, has consumed almost the entire year, leaving suppliers in the dark.

This carries costs for health in the rest of the UK. Associate membership of Horizon Europe, the flagship EU science funding programme, was one of the major advantages of the trade and cooperation agreement signed last year. This offered British universities and NHS trusts the ability to take part in flagship life sciences projects across the continent. But accession has been delayed since February as a negotiating tool.

A coalition of universities and trade associations across Europe has warned that this "lingering uncertainty risks endangering current and future plans for collaboration." 5 Our report shows that changing expectations after the 2016 referendum already saw the UK's funding share for health-related projects fall from $20 \%$ to $12 \%$. With bids going in now, the price is likely already being paid.

The ramifications could be worse if the UK followed through on threats to suspend the Northern Ireland Protocol. The EU has implied it would consider suspending some or all of the trade and cooperation agreement, plunging us back into a no deal scenario with no mutual recognition of safely made medicines, no more EHIC cards and even more border checks. ${ }^{6}$

Bringing medical supplies into the UK, or investing in their production, has already become less appealing. The government and pharmaceutical industry were quite successful in stopping immediate shortages from breaking out a year ago, but this came at the price of delaying changes and decisions. ${ }^{7}$ An investor or importer of medicines cannot know what the UK regulatory system will be in 2023, or whether the current rubber-stamping of EU approvals will continue.

From 1 January 2022, the UK will finally introduce full customs checks for imports. ${ }^{8}$ These were previously delayed for fear of worsening shortages. The "border challenges" associated with existing trade controls probably contributed to the recent disastrous shortage of blood tubes. January 2023 will be another danger point.

On the EU side the full battery of paperwork, checks and requirements has been applied from the start. This has contributed to exports of medicines to the single market stabilising at about one third below the $£ 1$ billion a month common before the referendum.

Partly in response to such trends, the UK's negotiators are circling the globe in a search for trade agreements. The trade department has repeatedly pledged that the NHS and the prices it pays for medicines are "off the table." But we heard at our roundtable and in interviews that whether or not these catchphrases actually rule out the main provisions that might cause problems for the health service is hard to say. ${ }^{9}$ Our analysis of meetings carried out by trade ministers supports a common view that engagement with the health sector has been minimal and mainly restricted to the pharmaceutical industry.

NHS procurement and migration rules might appear to be areas with clearer policy decisions. Many in the NHS welcomed the commitment to remove current rules on putting contracts out to the market for tender, and make it easier to simply roll them over. ${ }^{10}$ But we heard a wide range of views from officials and 
lawyers about what this would mean, with some feeling it might drive more cases to judicial review, some feeling it risked cartels, and considerable doubt over whether the amount of tenders would really decline or not.

The strict new visas now required for workers from the EEA, who previously enjoyed freedom of movement, are clear enough. But the effect they will have on staffing, especially in social care, is not. The pandemic has ruined data collection, and unusual trends in recruitment with the shutdown of other parts of the economy make it difficult to interpret staffing trends. ${ }^{11}$

However, recent data from social care shows an unprecedented drop of over 42000 in just six months. ${ }^{12}$ There is a risk that cutting off the migration that kept the sector slowly growing will combine with mandatory vaccinations and a recovering hospitality sector to create a genuinely catastrophic situation. The NHS leaders we spoke to, aware of trends in their local areas, almost universally put workforce at the top of their list of worries.

Far from being done, the impact of Brexit on health is only beginning to filter through. The ongoing lack of decisions, data and details in key areas magnifies uncertainty. It will add another dimension of disruption to a health service already struggling with the unknown legacy of a global pandemic on staff and patients.

Competing interests: none declared

Provenance and peer review: not commissioned, not peer reviewed

$1 \quad$ Nuffield Trust. Going it alone: Health and Brexit in the UK. December 2021. https://www.nuffieldtrust.org.uk/research/going-it-alone-health-and-brexit-in-the-uk

2 Bristows. EC proposals for Northern Ireland: A way forward for medicines? https://www.bristows.com/news/ec-proposals-for-northern-ireland-a-way-forward-for-medicines/

3 Government HM. Northern Ireland Protocol: the way forward. https://assets.publishing.service.gov.uk/government/uploads/system/uploads/attachment_data/file/1008451/CCS207_CCS0721914902-005_Northern_Ireland_ProtocoL_Web_Accessible_1_.pdf

4 European Commission. Proposal for a Directive of the European Parliament and of the Council. https://ec.europa.eu/info/sites/default/files/com_2021_997_1_en_act_part1_v1.pdf

5 All European Academies. ALLEA Signs Open Letter Calling for Finalising UK Association to Horizon Europe. https://allea.org/allea-signs-open-letter-calling-for-finalising-uk-association-to-horizoneurope/

6 The Irish Times. "Serious consequences" for EU-UK relations if article 16 triggered - Šefcovic. https://www.irishtimes.com/news/ireland/irish-news/serious-consequences-for-eu-uk-relationsif-article-16-triggered-\%C5\%A1efcovic-1.4729493

7 Nuffield Trust. What happened to those Brexit medicines shortages? https://www.nuffieldtrust.org.uk/news-item/what-happened-to-those-brexit-medicines-shortages

8 HM Revenue \& Customs. Less than a month until full customs controls are introduced. https://www.gov.uk/government/news/less-than-a-month-until-full-customs-controls-are-introduced

9 Nuffield Trust. Will the NHS be on the table for a Pacific trade deal? https://www.nuffieldtrust.org.uk/news-item/will-the-nhs-be-on-the-table-for-a-pacific-trade-deal

10 Provider Selection Regime NHS. Consultation on proposals. August 2021. https://www.england.nhs.uk/publication/nhs-provider-selection-regime-consultation-on-proposals/

11 The Migration Observatory. Where did all the migrants go? Migration data during the pandemic Feb 2021. https://migrationobservatory.ox.ac.uk/resources/commentaries/where-did-all-the-migrants-go-migration-data-during-the-pandemic/

12 Nuffield Trust. The tumbling numbers of social care staff. December 2021. https://www.nuffieldtrust.org.uk/resource/chart-of-the-week-the-tumbling-numbers-of-social-care-staff 